\title{
Qualidade de Água do Rio Cuiabá no Perímetro Urbano da Capital Mato-Grossense
}

\author{
Water Quality of Cuiabá River in the Capital Urban Perimeter
}

\author{
Jorge Luiz de Arruda*a; Ana Carolina Amorim Marques; ${ }^{\mathrm{a}}$ Osvaldo Borges Pinto Junior ${ }^{\mathrm{a}}$ \\ ${ }^{a}$ Universidade de Cuiabá, Programa de Pós-Graduação Stricto Sensu em Ciências Ambientais. MT, Brasil. \\ *E-mail: jorgearruda@ses.mt.gov.br
}

\begin{abstract}
Resumo
Este trabalho apresenta uma análise do índice e dos parâmetros de qualidade de água no perímetro urbano do rio Cuiabá - MT, considerando uma variação temporal (período úmido e seco) e espacial (montante - jusante) no ano de 2015. Os resultados mostraram que maiores valores de turbidez, sólidos totais, oxigênio dissolvido, demanda bioquímica de oxigênio e coliformes totais foram obtidos no período úmido e que os maiores valores de $\mathrm{pH}$, nitrogênio/nitrato e fósforo/fosfato ocorreram no período seco. O Índice de Qualidade de Água (IQA) foi maior no período seco em função de menores valores sólidos em suspensão, turbidez e coliformes totais. A análise da água da região perimetral ao rio Cuiabá demonstrou diferenças significativas entre os pontos mais a montante (Sucuri) em relação aos pontos a jusante (Porto e Caís) em ambos os períodos. Nesse sentido, o IQA foi menor nos pontos mais a jusante (Porto, Caís e Comunidade São Gonçalo Beira Rio) que nos pontos mais a montante (Sucuri e Ribeirão do Lipa). Os parâmetros estudados atendem a normatização da Resolução Conama 357/2005, apesar das diferenças no IQA para os pontos amostrados entre os períodos sazonais.
\end{abstract}

Palavras-chave: Efluente. Índice de Qualidade. Valoração Ambiental.

\begin{abstract}
This work presents an analysis of the index and water quality parameters in the urban perimeter of Cuiabá - MT, considering a temporal (rainy and dry period) and spatial (downstream) variation in the year 2015. Higher turbidity values, total dissolved oxygen, biochemical oxygen demand and total coliforms were obtained in the rainy season, while higher values of pH, nitrogen / nitrate and phosphorus / phosphate occurred in the dry period. IQA was higher in the dry period due to lower suspended solids, turbidity and total coliforms. The water analysis from the perimeter region to the Cuiabá river showed significant differences between the points upstream (Sucuri) in relation to the downstream points (Porto and Cais) in both periods. In this sense, the IQA was smaller in the points downstream (Porto, Caís and Comunidade São Gonçalo Beira Rio) than in the most upstream points (Sucuri and Ribeirao do Lipa). The studied parameters comply with the normalization of Conama Resolution 357/2005, despite the differences in the IQA for the points sampled between the seasonal periods.
\end{abstract}

Keywords: Effluent. Quality Index. Environmental Valuation.

\section{Introdução}

No Brasil, o saneamento ainda está muito aquém do ideal, principalmente, em relação à coleta e ao tratamento do esgoto sanitário. Embora o abastecimento de água esteja presente em cerca de $99 \%$ dos municípios brasileiros, índices bem inferiores caracterizam a coleta e tratamento de esgoto. De acordo com Sistema Nacional de Informações sobre Saneamento - SNIS, no Brasil, apenas 39\% dos esgotos gerados são tratados, vale ressaltar que o volume de esgotos aumentou de 3,586 bilhões de $\mathrm{m}^{3}$ em 2012 para 3,624 bilhões de $\mathrm{m}^{3}$ em 2013, o que corresponde a um aumento de $1,1 \%$ (BRASIL, 2013).

Atualmente, o crescimento populacional de Cuiabá-MT e a falta de infraestrutura vêm causando grandes prejuízos ambientais. As cidades de Cuiabá e Várzea Grande, no Estado de Mato Grosso, depositam diariamente cerca de 20 toneladas de resíduos sólidos (lixo doméstico) e industrial no rio Cuiabá (WOLMUTH; DINIZ, 2005). De acordo com o Plano Plurianual - PPA 2010-2013 da Prefeitura Municipal de Cuiabá, a cidade produz 230 ton./ano de lixo na forma de matéria orgânica, que se decompõe, gerando chorume, que vai escoar verticalmente em direção ao lençol freático (CUIABÁ, 2012).

O Trata Brasil (2015) cita que Cuiabá configura entre as capitais com piores índices em saneamento básico no ano de 2015 em relação aos anos anteriores, reduzindo os investimentos em 4,08\%. Com uma população de 569.830 habitantes, a capital de Mato Grosso está na $70^{\mathrm{a}}$ posição, entre as 100 cidades analisadas. A cidade tem apenas 35,3\% de rede de esgoto e desperdiça $67,2 \%$ de toda a água tratada, conforme o relatório. Conforme dados da prefeitura de Cuiabá, a população atendida pelos serviços de esgotos alcançou 47,83\% (266.921), com números de novas ligações atingindo 66.922 residências, com a rede de esgotos atingindo $767 \mathrm{~km}$, nos últimos três anos (ARSEC, 2015).

De acordo com informações do Plano Municipal de Saneamento Básico de 2014 (CNM, 2014), o sistema de esgotamento sanitário atende aproximadamente $38 \%$ da 
população, sendo que destes, somente $28 \%$ contam com os serviços de coleta e tratamento. Conforme Silva (2007), o rio Cuiabá segue em direção ao Pantanal depois de receber 4,3 litros por segundo de esgotos, todos os dias, apenas da capital do Estado, sendo que menos de $20 \%$ desse esgoto é tratado nas Estações de Tratamento de Esgoto (ETE's) existentes no município.

O lançamento de efluentes domésticos na área urbana de Cuiabá, combinado com o de indústrias e o aporte de matéria orgânica, nutrientes e pesticidas contribui para eutrofização deste ecossistema, que recebe um gradiente de fontes poluidoras de montante a jusante (referência). Espera-se, com isso, que a água coletada na região central da cidade de Cuiabá (bairro do Porto e Caís) apresente menor Índice de Qualidade de Água (IQA), decorrente do lançamento de efluentes in natura no rio, havendo diferença significativa entre os pontos a montante (Sucuri e Ribeirão da Ponte) e os pontos a jusante (Porto, Caís e Comunidade São Gonçalo Beira Rio). O perímetro urbano da cidade de Cuiabá (mais a jusante) concentra um número maior de residências e despejo direto de esgoto, que são lançados nos maiores córregos existentes na capital (Mané Pinto, Prainha, Gumitá e Barbado), além do rio Coxipó.

A qualidade de água foi avaliada seguindo o que é determinado pelo IQA e Resolução Conama 357/2005. O rio Cuiabá é classificado como rio de Classe 2 através da Resoluções Conama 357/2005 e 396/2008 e Resolução no 91 de 05 de novembro de 2008, pelo Ministério do Meio Ambiente/Conselho Nacional de Recursos Hídricos.

Nesse contexto, o objetivo geral deste trabalho foi avaliar a qualidade de água de acordo com o Índice de Qualidade de Água da National Sanitation Foundation (IQA-NSF) através da variação temporal (úmido e seco) e espacial (montantejusante), no perímetro urbano da cidade de Cuiabá-MT, no ano de 2015. Como objetivos específicos se tem a comparação dos nove parâmetros empregados para análise do Índice de Qualidade de Água - IQA-NSF e Resolução Conama 357/2005 das águas do rio Cuiabá no perímetro urbano de Cuiabá.

\section{Desenvolvimento}

\section{1 Área de estudo}

O estudo foi realizado no perímetro urbano de CuiabáMT (Figura 1), localizada na margem esquerda do rio Cuiabá, considerando um gradiente crescente de poluição, com pontos afastados da área mais urbanizada (montante): Comunidade Sucuri (P1) (15³3’21.0”'S; 56¹0’00.6”W), Estação de Captação de Água da $\mathrm{CAB}$ Ambiental do Ribeirão do Lipa (P2) (15³4'70.3'S; 5607'95.0” W); e pontos na área mais urbanizada da cidade (jusante): Estação de Captação de Água da CAB Ambiental do Bairro do Porto (P3) (15³7'25.2'S; $\left.56^{\circ} 06^{\prime} 87.5^{\prime} \mathrm{W}\right)$, Caís do Porto (P4) (15³7’059.1"S; $56^{\circ} 61$ '12.8”W), Comunidade São Gonçalo Beira Rio (P5)
(15³7'02.4’'S; 5606'0.59’'W).

Figura 1 - Pontos de coleta das amostras de água do rio Cuiabá, considerando um gradiente crescente de fontes poluidoras de montante (P1 - Sucuri) para jusante (P5 - São Gonçalo Beira Rio)

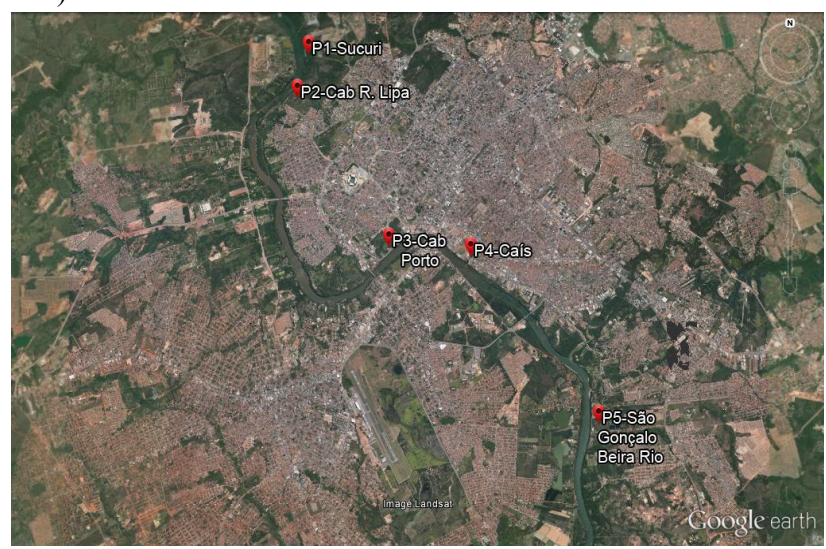

Fonte: Google Earth (2015).

\subsection{Coleta e a análise de dados}

Amostras de água foram coletadas na margem esquerda do rio Cuiabá, nos meses de janeiro e março (período úmido) e agosto (período seco) de 2015, sempre no período matutino, em cinco pontos de montante a jusante no perímetro urbano de Cuiabá. Em cada ponto, três amostras de água foram coletadas, manualmente, na região marginal (um metro) em frascos esterilizados.

As análises das amostras de água do rio Cuiabá foram feitas em laboratório através do Standard Methods $22^{\text {nd }}$, tendo como base a cromatografia de íons.

Os valores de precipitação pluviométrica dos meses de amostragem foram obtidos no INMET - Instituto Nacional de Meteorologia, para serem confrontados com os parâmetros utilizados para elaboração do IQA.

\subsection{Análises estatísticas dos dados}

Os resultados obtidos das amostras de água coletadas do rio Cuiabá foram descritos e analisados estatisticamente, a fim de identificar diferenças temporais (úmido e seco) e espaciais (montante - jusante).

Foram utilizadas como análises exploratórias multivariadas as análises de agrupamento ("Cluster Analysis") e de Ordenação por Escalonamento Multidimensional NãoMétrico (NMDS). Para tal, os dados ambientais foram transformados em $\log (\mathrm{x}+1)$ e a distância Euclidiana foi usada como índice de associação.

Foram feitos teste de normalidade (Shapiro-Wilks; $\alpha \geq 0,05$ ) e homocedasticidade (Levene; $\alpha \geq 0,05$ ), sendo levantadas duas hipóteses para análise temporal $(\mathrm{H} 0=$ Úmido=Seca; $\mathrm{H} 1=$ Úmido $\neq$ Seca) e para a análise espacial $(\mathrm{H} 0=$ não existe diferença entre os pontos; $\mathrm{H} 1$ = existe diferença entre os pontos).

Foi utilizada a análise de variância não-paramétrica de Kruskal-Wallis para testar a variação espacial (montante- 
jusante) e temporal (seco e úmido) dos 9 parâmetros da água analisados, sendo nos casos significativos seguidos de teste pareado de Conover-Inman, os dados de cada variável foram transformados em log (base 10).

\subsection{Resultados e Discussão}

Os valores de precipitação pluviométrica na região de Cuiabá obtidos a partir de dados registrados no INMET variaram de 0,2 a $68,2 \mathrm{~mm}$ na semana anterior a 25 de janeiro/2015. Estes valores estão inferiores ao esperado para o período, que é descrito como úmido (novembro a abril) (INMET, 2015). Em março/2015, a precipitação pluviométrica variou de 0,2 a $36,8 \mathrm{~mm}$ na semana anterior à coleta (23 a 28/03/15). Observa-se um maior volume de água no rio Cuiabá, Coxipó e nos Córregos canalizados da cidade, além de uma coloração amarronzada na água decorrente do carreamento de sedimentos.

No mês de agosto de 2015 não houve precipitação pluviométrica na semana de 31/07 a 07/08/2015 (INMET, 2015). Esta fase é considerada seca na região do Pantanal e a profundidade na região marginal do rio Cuiabá, no dia da coleta estava em 0,38 m (BRASIL, 2015).

Os maiores valores de turbidez, sólidos totais, oxigênio dissolvido, demanda bioquímica de oxigênio (DBO) e coliformes totais foram obtidos no período úmido (janeiro e março/2015), enquanto maiores valores de $\mathrm{pH}$, nitrato e fosfato ocorreram no período seco (agosto/2015). Diferenças significativas entre os períodos amostrais foram obtidas para todos os parâmetros avaliados $(p<0,05)$, exceto $\mathrm{DBO}$, que variou pouco nas épocas avaliadas (Quadro 1).

Quadro 1 - Média e Desvio Padrão dos parâmetros de qualidade de água no perímetro urbano do rio Cuiabá nos períodos úmido e seco (temporal), seguido pelo resultado da análise de variância de Kruskal-Wallis

\begin{tabular}{|c|c|c|c|c|c|}
\hline \multirow{2}{*}{ Variáveis } & \multirow{2}{*}{$\begin{array}{c}\begin{array}{c}\text { Resolução Conama } \\
\text { 357/2005 }\end{array} \\
\end{array}$} & \multirow{2}{*}{$\begin{array}{c}\text { ÚMIDO } \\
\text { Média } \pm D P\end{array}$} & \multirow{2}{*}{$\begin{array}{c}\text { SECO } \\
\text { Média } \pm \text { DP }\end{array}$} & \multicolumn{2}{|c|}{ Kruskal-Wallis } \\
\hline & & & & $\mathbf{H}$ & p-valor \\
\hline $\mathrm{CT}$ & Até $1.000 \mathrm{NMP} / 100 \mathrm{~mL}$ & $9120,50 \pm 7804,01$ & $18,91 \pm 16,07$ & 26,02 & 0,000 \\
\hline $\mathrm{pH}$ & De 6 até 9 & $6,80 \pm 0,12$ & $7,83 \pm 0,16$ & 24,54 & 0,000 \\
\hline TB & Até 100 NTU & $217,80 \pm 81,97$ & $10,73 \pm 11,49$ & 22,59 & 0,000 \\
\hline ST & Até $500 \mathrm{mg} / \mathrm{L}$ & $212,40 \pm 61,65$ & $68,00 \pm 36,75$ & 8,91 & 0,003 \\
\hline $\mathrm{N}$ & Até $0,10(\mathrm{mg} / \mathrm{L})$ & $0 \pm 01$ & $0,03 \pm 1,43$ & 30,97 & 0,000 \\
\hline OD & Não inferior a $5 \mathrm{mg} / \mathrm{L} \mathrm{O}^{2}$ & $8,60 \pm 0,66$ & $5,97 \pm 0,75$ & 24,60 & 0,000 \\
\hline DBO & Até $5 \mathrm{mg} / \mathrm{L} \mathrm{O}^{2}$ & $4,84 \pm 0,98$ & $4,78 \pm 0,65$ & 0,94 & 0,332 \\
\hline $\mathrm{P}$ & Até $0,10 \mathrm{mg} / \mathrm{L}$ & $0 \pm 01$ & $0,03 \pm 1,43$ & 34,00 & 0,000 \\
\hline Temp. $\left({ }^{\circ} \mathrm{C}\right)$ & -- & $27,45 \pm 1,03$ & $26,36 \pm 0,27$ & - & - \\
\hline
\end{tabular}

TB - Tubidez; ST - Sólidos Totais; N - Nitrato; OD - Oxigênio Dissolvido; DBO - Demanda Bioquímica de Oxigênio; P - Fosfato

Fonte: Dados da pesquisa.

Ao contrário do esperado, a água do rio Cuiabá apresentou melhor resultado no IQA no período seco, decorrente do menor carreamento de matéria orgânica das áreas a montante, que refletiram em baixos valores de turbidez e sólidos totais. Nesse sentido, apesar dos efluentes, possivelmente, estarem mais concentrados ao serem lançados na água do rio Cuiabá durante a seca, a concentração de coliformes totais e de outros parâmetros foram, significativamente, menores do que preconiza a Resolução Conama 357/2005 (Quadro 1).

$\mathrm{O}$ carreamento de matéria orgânica no período úmido decorrente do alto índice pluviométrico, que ocorreu nos meses de outubro a abril (média de 208,76 mm) (INMET, 2015), provavelmente, aumentou exponencialmente a atividade microbiológica na água, indicando uma relação entre os índices de coliformes totais e fecais e precipitação (VASCONCELOS; SERAFINI, 2002). Assim, com o aumento do índice pluviométrico ocorrido na semana da coleta (março de 2015), este pode ter interferido na qualidade da água do rio, aliado com a alta descarga de efluentes e a falta de cobertura vegetal que possibilitou o input de coliformes totais no rio.

A turbidez teve sua maior média no período úmido, uma vez que as partículas carreadas para dentro do leito do rio possibilitam o aumento dos sedimentos e na erosão de encostas das margens, contribuindo para um maior valor na turbidez (Quadro 1). Dutra et al. (2010) citam que no período de estiagem, a turbidez e o fosfato total permanecem menores do que no período úmido, em função da grande quantidade de material carregado pelas enxurradas, porém, o fosfato, neste trabalho, não esteve de acordo com os autores citados, já que o menor valor foi detectado no período úmido. Isso pode ter ocorrido em função da origem do material orgânico depositado, e que mesmo no período de estiagem a quantidade de material é, consideravelmente, mais concentrada, aumentando assim a quantidade de fosfato na água.

No período úmido houve um aumento considerável nos sólidos totais (ST); tal variação pode ter ocorrido em função do processo de erosão das margens do rio Cuiabá, desaparecimento da mata ciliar no perímetro urbano e da poluição ser crescente de montante a jusante (BERTOLDO, 2014) (Quadro 1).

Lougon et al. (2009) explicam que os sólidos agem de maneira indireta sobre a vida aquática, impedem a penetração da luz e induzem o aquecimento da água, o que, consequentemente, diminui a quantidade de oxigênio dissolvido no meio e a solubilidade dos gases na água diminui em função do aumento da temperatura, que exerce influência 
direta na dissolução do oxigênio na água (CALEGARI et al., 2015).

A concentração de sólidos totais tende a aumentar no período úmido por conta do carreamento de parte do solo para o leito do rio e, no caso do oxigênio dissolvido, este diminui, pois com o aumento da vazão há uma maior quantidade de matéria biodegradável (matéria orgânica), advinda dos esgotos domésticos, que são decompostas no ambiente aquático em uma quantidade alta e, no final, consome mais oxigênio.

O OD foi diferente entre os períodos, sendo maior no período úmido, variando entre 5,23-6,8 (seco) e de 7,83-9,43 (úmido). O oxigênio dissolvido na água não deve ser inferior a $5 \mathrm{mg} / \mathrm{L}$, e todas as amostras apresentaram valores acima do determinado pela Resolução Conama 357/05. Pinto et al. (2010) informam que o oxigênio é utilizado como principal parâmetro de qualidade da água e serve para determinar o impacto de poluentes sobre os corpos da água, portanto, as amostras avaliadas estão dentro do padrão permitido.

A DBO não apresentou diferença entre os períodos amostrais, pois não variou substancialmente. A DBO é definida como a quantidade de oxigênio necessária para oxidar a matéria orgânica biodegradável, sob condições aeróbicas, ou seja, avalia a quantidade de $\mathrm{OD}$ em $\mathrm{mg} / \mathrm{L}^{-1}$ de $\mathrm{O}_{2}$, que será consumido pelos organismos aeróbios ao degradarem a matéria orgânica (RODRIGUES et al., 2011). Nas condições deste estudo, a DBO não apresentou varrições entre os períodos em função da temporalidade amostral. Esperava-se que a DBO tivesse variações marcantes entre uma estação e outra.

$\mathrm{O}$ pH apresentou condições distintas, sendo mais ácido no período seco e mais alcalino no período seco (Tabela 1). A Resolução Conama 357/2005 cita que o pH de água de rio classe 2 deve ter valor compreendido entre 6,0 a 9,0 (BRASIL, 2005), dessa maneira, as amostras, tanto do período úmido quanto da seca, estão dentro dos parâmetros recomendados. $\mathrm{O}$ pH pode ser influenciado por despejos domésticos e/ou industriais, pelo tipo de solo e pela erosão de áreas agrícolas, que tenham recebido corretivos e fertilizantes (FRANCA et al., 2006).
O nitrato e o fosfato apareceram no período da seca apenas, demonstrando que ao longo do trecho analisado há pouca atividade que venha a depositar tais nutrientes no solo para serem carreados para o curso de água no período úmido. O fósforo é considerado um grande poluente de cursos de água, especialmente as águas superficiais, já que ocorre pouca percolação deste elemento (KLEIN; AGNE, 2012).

Silva (2014) relata que o aparecimento de fósforo nas águas do rio Cuiabá está relacionado com as atividades antrópicas, as que estão associadas à agricultura e aos aglomerados urbanos. Merecem destaque, entre essas atividades, o uso intensivo de fertilizantes fosfatados em áreas agrícolas e o lançamento de efluentes não tratados nos rios, os quais acarretam grande aporte de nutrientes, como o fósforo que, em excesso, desencadeia processo de eutrofização dos corpos de água, comprometendo, com isso, a qualidade da água, e ademais, o fósforo pode ser encontrado nos sedimentos nas formas ligadas ao cálcio, ao ferro e ao alumínio e em espécies orgânicas ou adsorvidas aos minerais.

O resultado do IQA do rio Cuiabá deve ser correlacionado com a variação da $\mathrm{DBO}$, dos coliformes totais, do OD e da turbidez, em relação ao aumento de sólidos totais nas águas do rio Cuiabá, sendo que, no período úmido, há o aumento de matéria orgânica carreada do solo para o leito do rio, a partir do lançamento direto de efluentes no rio e pela poluição difusa, ausência da mata ciliar e o uso e ocupação do solo entorno da margem do rio.

\subsection{Variação espaço-temporal da água do rio Cuiabá}

A análise dos parâmetros usados no cálculo do IQA-NSF entre os cinco pontos de coleta no rio Cuiabá demonstrou que existem diferenças, significativas, entre os pontos, tanto no período úmido, quanto no seco, para algumas variáveis. A concentração de coliformes totais e o oxigênio dissolvido diferiram, significativamente, de um ponto para outro em ambos os períodos, porém a demanda bioquímica de oxigênio variou significativamente apenas no seco $(\mathrm{p}<0,05)$ (Quadro 2).

Quadro 2 - Parâmetros de qualidade de água dos pontos de coleta (espacial) no perímetro urbano do rio Cuiabá nos períodos úmido e de seca, seguidos pelo resultado da análise de variância de Kruskal-Wallis $(\mathrm{p}<0,05)$

\begin{tabular}{|c|c|c|c|c|c|c|c|}
\hline \multirow{3}{*}{ Variáveis } & \multicolumn{7}{|c|}{ Úmido } \\
\hline & \multicolumn{5}{|c|}{ Pontos } & \multicolumn{2}{|c|}{ Kruskal-Wallis } \\
\hline & P1 & $\mathbf{P 2}$ & P3 & P4 & P5 & $\mathbf{H}$ & $p>0,05$ \\
\hline $\mathrm{CT}(\mathrm{NMP} / 100 \mathrm{~mL})$ & $887,50 \pm 65$ & $580 \pm 80$ & $12135 \pm 7730$ & $16000 \pm 0$ & $16000 \pm 0$ & 14,67 & 0,005 \\
\hline $\mathrm{pH}$ & $6,70 \pm 0,1$ & $6,70 \pm 0,17$ & $6,76 \pm 0,15$ & $7 \pm 0$ & $6,86 \pm 0,04$ & 3,23 & 0,51 \\
\hline TB(NTU) & $230,66 \pm 8,50$ & $87,36 \pm 3,69$ & $318,66 \pm 66,01$ & $235 \pm 8$ & $217,33 \pm 26,63$ & 5,49 & 0,24 \\
\hline ST (mg/L) & $266,00 \pm 26$ & $103,66 \pm 10,01$ & $248,00 \pm 22,27$ & $239 \pm 16$ & $205,33 \pm 3,77$ & 4,52 & 0,34 \\
\hline $\mathrm{N}(\mathrm{mg} / \mathrm{L})$ & $0 \pm 0$ & $0 \pm 0$ & $0 \pm 0$ & $0 \pm 0$ & $0 \pm 0$ & 2,25 & 0,69 \\
\hline $\mathrm{OD}(\mathrm{mg} / \mathrm{L})$ & $9,43 \pm 0,15$ & $9,00 \pm 0,1$ & $8,70 \pm 0,17$ & $8 \pm 0$ & $7,86 \pm 0,04$ & 16,57 & 0,00 \\
\hline $\mathrm{DBO}(\mathrm{mg} / \mathrm{L})$ & $5,63 \pm 0,58$ & $4,56 \pm 0,45$ & $5,63 \pm 0,58$ & $3 \pm 0$ & $5,36 \pm 0,23$ & 3,36 & 0,49 \\
\hline $\mathrm{P}(\mathrm{mg} / \mathrm{L})$ & $0 \pm 0$ & $0 \pm 0$ & $0 \pm 0$ & $0 \pm 0$ & $0 \pm 0$ & 0,00 & 1,00 \\
\hline Temp $\left({ }^{\circ} \mathrm{C}\right)$ & $26,75 \pm 1,50$ & $27,50 \pm 1$ & $27,50 \pm 1$ & $28 \pm 1$ & $27,50 \pm 0,86$ & - & - \\
\hline
\end{tabular}




\begin{tabular}{|l|l|l|l|l|l|l|l|}
\hline \multicolumn{7}{|c|}{ Variáveis } & \multicolumn{9}{|c|}{ Seco } & \multicolumn{2}{c|}{ Kruskal-Wallis } \\
\hline & \multicolumn{7}{|c|}{ Pontos } \\
\hline & P1 & P2 & P3 & P4 & P5 & H & $\boldsymbol{p}>\mathbf{0 , 0 5}$ \\
\hline CT NMP/100mL) & $1,79 \pm 0$ & $1,79 \pm 0$ & $18 \pm 0$ & $36 \pm 0$ & $37 \pm 0$ & 14,00 & 0,007 \\
\hline pH & $7,85 \pm 0,26$ & $7,99 \pm 0,04$ & $7,91 \pm 0,07$ & $7,65 \pm 0,08$ & $7,77 \pm 0,10$ & 7,01 & 0,13 \\
\hline TB $(\mathrm{NTU})$ & $5,12 \pm 1,21$ & $4,42 \pm 1,00$ & $19,37 \pm 22,36$ & $5,38 \pm 1,26$ & $19,36 \pm 6,90$ & 9,54 & 0,04 \\
\hline ST $(\mathrm{mg} / \mathrm{L})$ & $108 \pm 17,43$ & $62,66 \pm 37,80$ & $70,66 \pm 56,75$ & $52 \pm 8$ & $46,66 \pm 30,28$ & 5,20 & 0,26 \\
\hline $\mathrm{N}(\mathrm{mg} / \mathrm{L})$ & 0,030 & 0,03 & 0,03 & 0,03 & 0,03 & 0,00 & 1,00 \\
\hline OD $(\mathrm{mg} / \mathrm{L})$ & $6,80 \pm 0,27$ & $6,23 \pm 0,11$ & $6,30 \pm 0,44$ & $5,23 \pm 0,42$ & $5,28 \pm 0,86$ & 10,55 & 0,03 \\
\hline DBO $(\mathrm{mg} / \mathrm{L})$ & $4,93 \pm 0,20$ & $4,50 \pm 0,62$ & $5,40 \pm 0,3$ & $4,06 \pm 0,64$ & $5 \pm 0,7$ & 8,14 & 0,08 \\
\hline $\mathrm{P}(\mathrm{mg} / \mathrm{L})$ & $0,03 \pm 0$ & $0,03 \pm 0$ & $0,03 \pm 0$ & $0,03 \pm 0$ & $0,03 \pm 0$ & 0,00 & 1,00 \\
\hline Temp $\left({ }^{\circ} \mathrm{C}\right)$ & $26,5 \pm 0,03$ & $26,1 \pm 0,05$ & $26,63 \pm 0,06$ & $26,50 \pm 0$ & $26,5 \pm 0,17$ & - & - \\
\hline
\end{tabular}

Fonte: Dados da pesquisa.

No período úmido, a turbidez variou significativamente nos pontos 1, 3, 4 e 5, ou seja, mais que o dobro permitido pela Resolução Conama 357/2005, no entanto, no ponto 2, a turbidez ficou abaixo do que a Resolução Conama 357/2005 determina, que é de 100 NTU.

De forma geral, os pontos 3, 4 e 5 apresentam maiores valores de coliformes totais e turbidez e menores valores de oxigênio dissolvido, tanto no período úmido quanto no seco (Quadro 2). Estes pontos são mais poluídos recebendo diretamente efluentes da região urbana de Cuiabá e, por isso, apresentam um menor índice de qualidade de água em relação aos pontos $1 \mathrm{e} 2$, indicando um gradiente de fontes poluidoras, que é de certa forma mantido temporalmente.

Este gradiente crescente de poluição não foi observado para os parâmetros sólidos totais dissolvidos e DBO, sendo os sólidos totais maiores no ponto 1 (Sucuri, ponto mais a montante) que é aparentemente menos poluído; e a DBO menor no ponto 4 (Caís do Porto), mais poluído, em ambos os períodos (Quadro 2).

$\mathrm{O}$ nitrato e o fosfato não apresentaram diferenças espaciais em ambos os períodos, não sendo detectados no período úmido e ocorrendo em baixa quantidade no seco e de forma constante em todos os pontos $(0,03 \mathrm{mg} / \mathrm{L}$ ) (Quadro 2).

A água do rio Cuiabá nos meses de seca é menos oxigenada, em que o lançamento de cargas orgânicas é mais acentuado, porém em função de uma característica física no trecho do rio no qual foi realizada a coleta (Caís do Porto e São Gonçalo Beira Rio), a assimilação da carga orgânica é menor, o que pode reduzir a demanda bioquímica de oxigênio em decorrência de corredeiras, principalmente, no período de seca, no qual pedras afloram, tanto que no Caís do Porto (P4) a turbidez fugiu ao gradiente crescente de poluição esperado (LIBOS; LIMA, 2002), sendo maior apenas nos pontos 3 e 5.

A DBO encontrada nos pontos 1 e 2, no período de seca, está abaixo do limite permitido pela Resolução Conama 357/05. Segundo Matos (2004), a determinação da demanda bioquímica de oxigênio em águas superficiais tem sido utilizada com o intuito de se ter uma ideia do grau de poluição orgânica dos corpos hídricos, sendo uma das variáveis mais importantes na determinação da qualidade da água, dessa maneira, a água do rio Cuiabá coletada nos pontos 1 a 5 , somente teve valores superiores ao determinado pela resolução apenas no ponto 1,3 e 5 . Os valores superiores estão próximos ao permitido, permitindo assim inferir que a qualidade de água do Rio Cuiabá apresenta qualidade adequada, quando se observa a DBO.

A turbidez e os sólidos totais dissolvidos foram maiores nos pontos 1, 3, 4 e 5 no período úmido, porém é importante destacar que esta variável, no ponto 1 (Comunidade Sucuri), apresentou valor bastante elevado de turbidez. Já os sólidos totais, além de apresentarem maiores valores no período úmido, também se apresentaram elevados no período de seca no ponto 1 ; talvez, em decorrência da bomba de captação de água da $\mathrm{CAB}$ Ambiental ou mesmo pelo carreamento de resíduos sólidos da parte monte ao ponto de coleta (Quadro 2).

Quanto aos coliformes totais e o OD, quanto mais se adentra para o setor urbano, maior será a variação, uma vez que a descarga de esgotos no rio Cuiabá é grande. Entre a Comunidade Sucuri até a Comunidade São Gonçalo Beira Rio foram avistados oito córregos desaguando no rio Cuiabá, sendo alguns desses canalizados e utilizados para escoar efluentes domésticos das residências cuiabanas. Esses canais recebem águas pluviais que são drenadas juntamente com esgoto para o rio Cuiabá. Assim, estes córregos foram descaracterizados, necessitando de investimentos públicos para drenar todo esgoto para uma ETE e para recuperar os trechos que ainda não foram canalizados.

Os pontos 3, 4 e 5 apresentaram altos valores de coliformes totais no período úmido, provavelmente, pelo carreamento de material do solo para as águas do rio Cuiabá neste período, possivelmente, em função de uma grande descarga de esgoto advinda dos córregos Mané Pinto e da Prainha e, talvez, também, dos vários empreendimentos que existem nas proximidades do rio, os quais podem também estar lançando seus dejetos diretamente no rio (Quadro 2).

No caso do $\mathrm{pH}$, houve pouca variação temporal entre os períodos, sendo em média menor a montante e maior a jusante no período úmido, e sem padrão espacial no período seco, em que o valor mínimo foi de 7,56 e o máximo de 8,08, ambos no ponto 1 (Quadro 2). 
Esses resultados demonstram que o potencial poluidor de efluentes domésticos lançados diariamente no rio Cuiabá, na parte urbana da capital Mato-Grossense, pode causar um impacto negativo ao ecossistema aquático local, implicando em uma perda ambiental considerável decorrente de mau gerenciamento dos resíduos gerados, comprometendo, assim, a qualidade das águas do rio no trecho localizado entre o bairro do Porto até a Comunidade São Gonçalo Beira Rio. Moreschi et al. (2015) relatam que o lançamento pontual de carga orgânica de esgoto doméstico, com concentrações elevadas de DBO, faz com que o corpo receptor se torne um ambiente anóxico, podendo provocar a morte de espécies aquáticas e resultando na recuperação de suas águas apenas a partir de quilômetros abaixo.

\section{Conclusão}

Existe concentração maior de poluentes no perímetro urbano do rio Cuiabá, no período úmido, diferentemente do que era esperado, pois apesar da descarga de efluentes ser semelhante em ambos os períodos, o aumento do volume do rio Cuiabá no período úmido não causa diluição desses efluentes, mas carreia matéria orgânica, interferindo diretamente nos parâmetros que compõem o IQA. Dessa forma, com exceção do $\mathrm{pH}$, que teve alta na seca, os outros parâmetros aumentaram no período úmido, com diferenças significativas relacionadas ao carreamento de matéria orgânica e, possivelmente, produtos químicos advindos do solo para o rio.

Em relação aos pontos amostrais, evidenciou-se que a relação montante-jusante esperada foi observada, ou seja, os pontos 1 e 2 mais a montante (Sucuri e Ribeirão do Lipa) apresentaram melhor qualidade de água em relação aos pontos mais a jusante (3, 4 e 5; Porto, Caís e Comunidade São Gonçalo Beira Rio, respectivamente) relacionados com descargas de efluentes e carreamento de material em suspensão.

Quanto ao IQA-NSF, no perímetro urbano do rio Cuiabá, no período úmido, a qualidade de água foi menor, sendo classificada como "Regular ou Aceitável" em relação ao período de seca ("Boa"), provavelmente em função do aumento de material em suspensão. Diferenças espaciais (pontos de coleta) foram obtidas para o IQA-NSF, tanto no período úmido quanto no seco, sendo perceptível um gradiente de redução da qualidade da água de montante para jusante.

Este gradiente de redução da qualidade de água de montante para jusante, sobretudo, no período úmido, foi corroborado pela análise de agrupamento e ordenação, comprovando que o lançamento de efluentes na região central de Cuiabá e fontes difusas de poluição (matéria orgânica assoreada, por exemplo) comprometem a qualidade de água nas estações de captação. Assim, observou-se maior similaridade entre os pontos de coleta mais a montante ( 1 e 2 ) e entre os pontos mais a jusante (3, 4 e 5), nas diferentes datas amostrais (úmido e seco) e a separação destes em relação aos parâmetros utilizados para o cálculo do IQA-NSF.

Os resultados alcançados atendem à normatização da
Resolução Conama 357/2005 quanto à análise dos nove parâmetros estudados, por mais que haja uma variação alta entre a variação temporal (úmido e seco) no índice de qualidade de água do rio Cuiabá nos cincos pontos de coleta, observase que a variação ocorre em decorrência do carreamento do solo para o leito do rio, no período úmido, combinado com a degradação da mata ciliar, bem como do aumento populacional na área urbana de Cuiabá, em que a descarga de efluentes in natura sem nenhum tipo de tratamento é lançado diariamente no rio Cuiabá.

\section{Referências}

ARSEC - Agência municipal de regulação de serviços públicos delegados de Cuiabá. Relatório da evolução dos indicadores de qualidade: abastecimento de água e esgotamento sanitário de Cuiabá, MT. 2015. Disponível em: <http:// www.cuiaba.mt.gov.br/storage/webdisco/2016/01/19/outros/ b0c84b7f4944b80bfe03c44fbe603d0c.pdf >. Acesso em: $10 \mathrm{abr}$. 2020.

BERTOLDO, D.C. et al. Análises físico-químicas das águas do rio do Ouro, em Ouro Verde do Oeste - Paraná. Inic. Cient. Cesumar, v.6, n.2, p.147-154, 2014.

BRASIL. M.M.A. Resolução N. ${ }^{\circ} 357$ de 17 de março de 2005: Dispõe sobre a Classificação dos Corpos D'Água e Diretrizes Ambientais para o seu enquadramento, Bem como Estabelece as Condições e Padrões de Lançamento de Efluentes. Brasília: Diário Oficial da União, 18 de março de 2005.

BRASIL, M. Nivel do rio Cuiabá. Disponível em: <https://www. mar.mil.br/ssn-6/altura_cuiaba.pdf $>$. Acesso em: 13 nov. 2019.

Brasil, Ministério das Cidades. Secretaria Nacional de Saneamento Ambiental - SNSA. Sistema Nacional de Informações sobre Saneamento. Diagnóstico dos Serviços de Água e Esgotos. Brasília: SNSA/MCIDADES, 2014. 181 p.: il. 2013.

Confederação Nacional de Municípios-CNM. Planos Municipais de Saneamento Básico: Orientações para Elaboração. Brasília: CNM, 2014.

CALEGARI, R.P. et al. Caracterização da água da microbacia do Rio Lonqueador avaliada por parâmetros físicos, químicos e microbiológicos. Reget, v. 19, n.2, p.1284-91, 2015.

CUIABÁ. P.M. Plano Plurianual - PPA - 2010 / 2013. Cuiabá: Secretaria Municipal de Planejamento, Orçamento e Gestão, Diretoria de Planejamento e Programação Orçamentária, 2012.

DUTRA, F.M. et al. Avaliação da qualidade físico-química da água no rio Itapemirim no período úmido e seco. Unioeste, Disponível em: http:/cac-php.unioeste.br/eventos/senama/anais/ PDF/RESUMOS/147_1269889148_RESUMO.pdf. Acesso em: 20 mar. 2020.

FRANCA, R.M, et al. Contaminação de poços tubulares em Juazeiro do Norte-CE. Eng. Sanitária Amb., v.11, n.1, p. 92-102, 2006.

INMET - Instituto Nacional de Meteorologia. Dados Históricos. Disponível em: <http://www.inmet.gov.br/projetos/rede/ pesquisa/gera_serie_txt_mensal.php?\&mRelEstacao $=83361 \&$ btnProcesso $=\overline{\text { serie }} \& \mathrm{~m}$ RelDtInicio $=30 / 07 / 2015 \& \mathrm{mRe}$ elDtFim $=07 / 08 / 2015 \& m$ Atributos $=, 1,,,,,,,, 1,,,, 1,1,1,>$. Acesso em: 10 set. 2020 .

KLEIN, C; AGNE, S.A.A. Fósforo: de nutriente à poluente! Rev. Elet. Gestão, Educ. Tecnol. Amb., v.8, n.8, p. 1713-1721, 2012.

LIBOS, M.I.P.C.; LIMA, E.B.N.R. Impactos das contribuições 
de efluentes domésticos e industriais na qualidade da água na bacia do rio Cuiabá-perímetro urbano. In: SIMPÓSIO ÍTALO-BRASILEIRO DE ENGENHARIA SANITÁRIA E AMBIENTAL, $p$. 1-6, 2002.

LOUGON, M.S. et al. Caracterização dos sólidos totais, fixos e voláteis nas águas residuárias geradas pela lavagem dos frutos do cafeeiro. In: ENCONTRO LATINO AMERICANO DE INICIAÇÃO CIENTÍFICA E ENCONTRO LATINO AMERICANO DE PÓS-GRADUAÇÃO - Universidade do Vale do Paraíba. 2009.

MATOS, A.T. Práticas de qualidade do meio físico e ambiental. Viçosa: Aeagri, 2004.

MORESCHI, I.C; PAES, R.P; CALHEIROS, D.F. Poluição Difusa na Bacia Hidrográfica do Rio Miranda, Mato Grosso do Sul. E\&S-Eng. Scie., v.2, n.4, p.2358-5390, 2015.

PINTO, A.L.; OLIVEIRA, G.H.; PEREIRA, G.A. Avaliação da eficiência da utilização do oxigênio dissolvido como principal indicador da qualidade das águas superficiais da bacia do córrego Bom Jardim, Brasilândia/MS. Rev. Geomae, v.1, n.1, p.69-82, 2010.

RODRIGUES, B. et al. Alterações da demanda bioquímica de oxigênio (DBO) em água causada por preparações homeopáticas. FÓRUM REGIONAL DE AGROECOLOGIA "SEMEANDO
OPORTUNIDADES, COLHENDO UM FUTURO", 9 a 11 de junho de 2011.

SILVA, E.A. Água de consumo humano: escassez na abundância e contaminação microbiológica nos períodos de cheia e seca Pantanal de MT. Cuiabá: Universidade Federal de Mato Grosso, 2007.

SILVA, D.A. Avaliação espaço-temporal da distribuição de fósforo na água e nos sedimentos de fundo das sub-bacias dos rios Cuiabá e São Lourenço e em algumas baias do Pantanal Mato-grossense. Araraquara: Universidade Estadual Paulista Júlio de Mesquita Filho, 2014.

TRATA BRASIL. Cuiabá e Várzea Grande estão entre as piores em saneamento. Disponível em: <http://www.tratabrasil.org.br/ cuiaba-e-varzea-grande-estao-entre-as-piores-em-saneamento $>$. Acesso em: 4 mar. 2020.

VASCONCELOS, S.M.S, SERAFINI, A.B. Ocorrência de indicadores de poluição no rio Meia Ponte e ribeirão João Leite, Goiás: coliformes totais e fecais. Rev. Patol. Trop., v.31, n.2, p.175-193, 2002.

WOLMUTH, L.D, DINIZ, G.L. Contaminação do rio Cuiabá por esgoto. Relatório técnico. 2005. Disponível em: http://www. ufmt.br/icet/matematica/geraldo/relat 2005 1.pdf. Acesso em: 30 set. 2020 . 